\title{
Разработка и валидация методики количественного определения нового антитромботическоголекарственного средства в плазме крови крыс методом ВЭЖХ
}

\author{
Леонов К.А. ${ }^{1}$, Вишенкова Д.А. ${ }^{1}$, Бакибаев А.А. ${ }^{2}$ \\ ${ }^{1}$ ФГАОУ ВО Наииональный исследовательский Томский политехнический университет, Томск \\ ${ }^{2}$ ФГАОУ ВО Национальный исследовательский Томский государственный университет, Томск
}

Поступила в редакцию 17.10.2016 г.

\begin{abstract}
Разработана биоаналитическая методика количественного определения нового антитромботического лекарственного средства GRS в плазме крови крыс методом ВЭЖХ с УФ-детектированием. Для выделения GRS из биологической матрицы использовали жидкостно-жидкостную экстракцию ацетонитрилом по принципу QuEChERS. Анализ проводили на хроматографе Милихром A-02 co спектрофотометрическим детектированием при 360 нм. В качестве подвижной фазы использовали $0.01 \mathrm{M}$ раствор аммония ацетата с $\mathrm{pH}$ равным 4.0 и метанол. Предел количественного определения GRS составил 10 нг/мл. С помощью валидации доказана пригодность разработанной методики для различных фармакокинетических исследований.
\end{abstract}

Ключевые слова: GRS, плазма крови, ВЭЖХ, валидация.

\section{Development and validation of technique of new antithrombotic drug quantitative determination in rats blood plasma by HPLC}

\author{
Leonov K.A. ${ }^{1}$, Vishenkova D.A. ${ }^{1}$, Bakibaev A.A. ${ }^{2}$ \\ IFSAEU of HE National Research Tomsk Polytechnic University, Tomsk \\ 2FSAEU of HE National Research Tomsk State University, Tomsk
}

High death and disability rates from cardiovascular disease are one of the key problems of medicine. Thrombotic events, along with hypertension and ischemic heart and brain tissue are the main causes of such life-threatening conditions such as: acute coronary syndrome, myocardial infarction, stroke.

Currently, a search of new medicines for the treatment of thrombosis and prevention is relevant. One of the main aspects of the study of innovative drugs is to study its pharmacokinetic properties, conducted in order to identify characteristics of absorption, distribution, conversion in the body, and excretion of a drug. These studies are obligatory for all new drugs. The most important step in the study of pharmacokinetics is the development and validation of bioanalytical methods of quantitative determination of the drug in the blood plasma of laboratory animals.

The aim of this work was the development and validation of bioanalytical methods of quantitative determination of a new innovative drug - platelet aggregation inhibitor (GRS) in the blood plasma of rats by HPLC.

Quantitative determination of the GRS in rat plasma was carried out on the chromatograph Milichrom-A02 (CJSC "EcoNova", Novosibirsk) column measuring $75.0 \times 2.0 \mathrm{~mm}$ filled with sorbent ProntoSIL $\mathrm{C} 18,5$ micron, and spectrophotometric detection at $360 \mathrm{~nm}$. The mobile phase A used $0.01 \mathrm{M}$ ammonium acetate solution of $\mathrm{pH}$ equal to 4.0 and mobile phase B - methanol. Eluent flow rate was $0.15 \mathrm{ml} / \mathrm{min}$, column temperature $-35^{\circ} \mathrm{C}$, sample injection volume - 20 microliters. Liquid-liquid acetonitrile extraction method was used for GRS extraction from plasma in accordance with QuEChERS principle. 
The validation was carried out to confirm the suitability of the developed method. Selectivity of techniques and its linearity were proven in the concentration range from 10 to $750 \mathrm{ng} / \mathrm{ml}$. Correctness of the method is from 93.0 to $99.9 \%$, and its accuracy - from 95.2 to $97.1 \%$.

The developed method can be used to quantify the GRS content in blood plasma of rats at different pharmacokinetic studies.

Keywords: GRS, blood plasma, HPLC, validation.

\section{Введение}

Высокая смертность и инвалидизация от сердечно-сосудистых заболеваний одна из ключевых проблем медицины. Их доля в общей смертности в России составляет 57 \%. Одна из основных причин этого явления - атеросклероз, развивающийся при наличии большого количества липопротеинов низкой плотности, которые малорастворимы и склонны к выделению в осадок кристаллов холестерина и формированию атеросклеротических бляшек в сосудах. Наличие таких бляшек вследствие повышения агрегационной способности тромбоцитов способствует образованию тромбов, которые могут внезапно перекрыть кровоток. Тромбообразование наряду с артериальной гипертензией и ишемией тканей сердца и головного мозга являются основными причинами развития таких смертельно опасных состояний, как: острый коронарный синдром, инфаркт миокарда, инсульт [1-3].

В настоящее время актуален поиск новых лекарственных средств для лечения и профилактики тромбообразования [4-5]. Одним из главных аспектов исследования инновационных лекарственных препаратов является изучение его фармакокинетических свойств, которое позволяет обосновать выбор путей и методов введения препарата, установить зависимость «концентрация-эффект», а также оптимизировать выбор его лекарственной формы. Фармакокинетическое исследование проводится с целью изучения особенностей всасывания, распределения, превращения в организме и выведения из организма лекарственного средства. Данные исследования обязательны для всех новых лекарственных препаратов [6-7]. Важнейшим этапом в исследовании фармакокинетики является разработка и валидация биоаналитической методики количественного определения лекарственного средства в плазме крови лабораторных животных.

Целью настоящей работы являлась разработка и валидация биоаналитической методики количественного определения нового инновационного лекарственного средства - ингибитора агрегации тромбоцитов в плазме крови крыс методом ВЭЖХ.

\section{Эксперимент}

Аппаратура. Количественное определение нового инновационного антитромботического лекарственного средства (кодовое название - GRS) [8] в плазме крови крыс осуществляли на хроматографе Милихром А-02 (ЗАО «ЭкоНова», г. Новосибирск) с УФ-детектором. Хроматографическое разделение проводили на колонке размером $75 \times 2$ мм, заполненной сорбентом ProntoSIL $\mathrm{C}_{18}, 5$ мкм. Сбор и обработку данных выполняли при помощи программного обеспечения «Мультихром» (ЗАО «Амперсенд», Россия). В процессе подготовки проб использовали лабораторную центрифугу Heraeus Biofuge pico (Германия), лабораторный встряхиватель Elmi V-3 (Латвия) и вакуумный концентратор UniEquip Univapo 100 ECH (Германия).

Реактивы. В работе применяли образец субстанции GRS $\left(\mathrm{C}_{15} \mathrm{H}_{13} \mathrm{~N}_{3} \mathrm{O}_{3}\right)$ произведенной ООО «Ифар» (г. Томск, Россия). Химическое наименование по IUPAC: 2-[2-[(5RS)-5-(гидроксиметил)-3-метил-1,3-оксазолидин-2-илиден]-2-

Леонов и др. / Сорбционные и хроматографические процессы. 2017. Т. 17. № 3 
цианоэтилиден]-1H-индол-3(2H)-он. Структурная формула GRS представлена на рис. 1.<smiles>CN1CC(CO)OC1=C(C#N)C=C1Nc2ccccc2C1=O</smiles>

Рис. 1. Структурная формула GRS

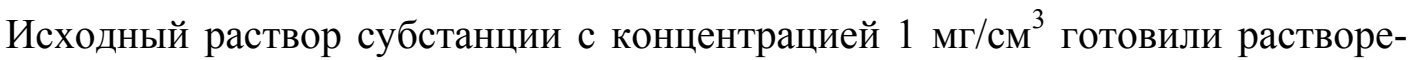
нием соответствующей навески в метаноле.

В качестве биологической матрицы использовали плазму крови крыс, не получавших субстанцию GRS. Калибровочные растворы GRS в плазме крови крыс готовили в день использования. Для приготовления подвижной фазы применяли метанол марки HPLC Grade (J.T.Baker, CША), аммония ацетат 99.5\% (Panreac, CША), кислоту уксусную ледяную $99.5 \%$ (Panreac, США), бидистиллированную воду (ГОСТ 7602-72). Для пробоподготовки использовали ацетонитрил марки «для ВЭЖХ» (ООО «НПК Криохром», Россия) и натрия хлорид марки «Хч» (ЗАО «Купавнареактив», Россия).

Пробоподготовка. Для извлечения GRS из плазмы крови использовали метод жидкостно-жидкостной экстракции ацетонитрилом по принципу QuEChERS (Quick, Easy, Cheap, Effective, Rugged, Safe). В пластиковую центрифужную микропробирку типа «Эппендорф» вместимостью $2 \mathrm{~cm}^{3}$ помещали 700 мкл плазмы крови крыс, содержащей GRS, прибавляли 1300 мкл ацетонитрила и тщательно перемешивали на встряхивателе Elmi V-3 при скорости 4000 об/мин в течение 5 мин. К смеси прибавляли 0.1-0.2 г натрия хлорида и 5 мин тщательно перемешивали. Полученный раствор центрифугировали 10 мин при 13000 об/мин. Водную фазу отбрасывали, а органическую упаривали на вакуумном концентраторе при температуре $45^{\circ} \mathrm{C}$ в течение 120 мин. К сухому остатку прибавляли 50 мкл смеси метанол - ПФ А в соотношении 1:1, тщательно перемешивали и центрифугировали 10 мин при 13000 об/мин. Надосадочную жидкость использовали для хроматографического анализа. Кратность концентрирования образца, согласно данной процедуре пробоподготовки, составляет 14 раз.

Условия хроматографического анализа. В качестве подвижной фазы А использовали $0.01 \mathrm{M}$ водный раствор аммония ацетата с $\mathrm{pH}$ равным 4.0, доведенным кислотой уксусной ледяной. В качестве подвижной фазы Б использовали метанол. Режим элюирования - градиентный, условия представлены в таблице 1. Скорость потока подвижной фазы составляла $0.15 \mathrm{~cm}^{3} / \mathrm{Mин}$, температура колонки $-35^{\circ} \mathrm{C}$, объем вводимой пробы - 20 мкл, длина волны УФ-детектирования - 360 нм.

Таблица 1. Условия градиентного режима элюирования

\begin{tabular}{|c|c|c|c|}
\hline Ступень градиента & Время, мин & Доля элюента А, \% & Доля элюента Б, \% \\
\hline Кондиционирование & 10 & 90 & 10 \\
\hline 1 & 5 & $90-40$ & $10-60$ \\
\hline 2 & 15 & $40-10$ & $60-90$ \\
\hline 3 & 20 & 10 & 90 \\
\hline
\end{tabular}

\section{Обсуждение результатов}

Обоснование выбора условий хроматографического анализа. Действующее вещество субстанции GRS обладает основными свойствами, и целесообразно было 
бы определять его при щелочном значении рН в молекулярной форме, однако ввиду постепенного растворения $\mathrm{C}_{18}$-силикагелей при щелочном значении $\mathrm{pH}$ [9], определение оснований проводят при кислом значении $\mathrm{pH}$ подвижной фазы в виде их ионных форм. Ионные формы удерживаются в обращенно-фазовом режиме значительно хуже, чем молекулярные [9], в связи с этим, для большего удерживания полярных соединений, при их определении в условиях низких значений $\mathrm{pH}$ элюента, используют добавку неорганической соли в подвижную фазу [10]. Именно поэтому, использовали в качестве подвижной фазы А 0.01 М раствор аммония ацетата с $\mathrm{pH}$ равным 4.0, доведенным уксусной кислотой ледяной. Значение оптимального $\mathrm{pH}$ раствора, в котором действующее вещество субстанции GRS будет находиться в одной ионной форме, было рассчитано с помощью программы ACD Labs 6.0. Выбор аммония ацетата в качестве неорганической солевой добавки обусловлен также его хорошей растворимостью в метаноле, используемом в качестве подвижной фазы Б, в котором определяемое вещество растворимо лучше, чем в ацетонитриле.

Условия градиентного режима хроматографического анализа подбирали с учетом оптимального времени удерживания целевого аналита при анализе экстрактов из биологической матрицы, где множество пиков элюирующихся веществ плазмы крови может накладываться на пик определяемого компонента.

Выбор рабочей длины волны спектрофотометрического детектора жидкостного хроматографа обусловлен максимумом поглощения (360 нм) на УФ-спектре раствора субстанции GRS в метаноле, записанного на спектрофотометре Perkin Elmer Lambda 14P и представленного на рис. 2.

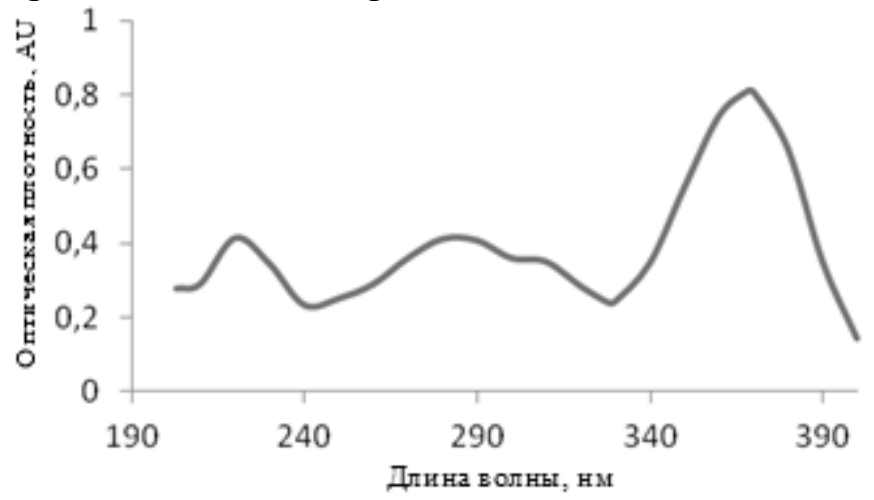

Рис. 2. УФ-спектр раствора субстанции GRS в метаноле

Выбор условий подготовки проб. Наиболее распространенными методами пробоподготовки при извлечении лекарственных веществ из плазмы крови являются осаждение белков, жидкостно-жидкостная экстракция (ЖЖЭ) и твердофазная экстракция (ТФЭ) [11]. При осаждении белков плазмы крови чаще всего не удается избавиться от переноса эндогенных веществ матрицы в аналит, что мешает селективности анализа. Использование метода ЖЖЭ при анализе большого количества образцов плазмы крови в исследованиях фармакокинетики является более экономичным, чем применение дорогостоящих картриджей ТФЭ. В связи с этим, нами был выбран метод жидкостно-жидкостной экстракции ацетонитрилом по принципу QuEChERS, основанный на извлечении определяемого компонента из сложной биологической матрицы ацетонитрилом, с последующим разделением водноорганического слоя с помощью натрия хлорида [12].

Валидация методики. Валидацию разработанной биоаналитической методики количественного определения GRS в плазме крови крыс проводили на основании «Руководства по экспертизе лекарственных средств. Том 1» (Россия, 2013) и согласно требованиям руководств по валидации биоаналитических методик «Guidance for 
Industry: Bioanalytical method validation» (FDA, CША, 2001) и «Guideline on validation of bioanalytical methods» (EMA, Англия, 2009) по следующим характеристикам: селективность, предел обнаружения и нижний предел количественного определения, линейность, правильность и прецизионность, перенос, стабильность.

Селективность. Для подтверждения селективности биоаналитической методики анализировали 6 образцов плазмы крови, не содержащих GRS (холостых образцов) и 6 образцов плазмы крови, содержащих GRS в концентрации $500 \mathrm{Hг} / \mathrm{cm}^{3}$. Полученные хроматограммы приведены на рис. 3.

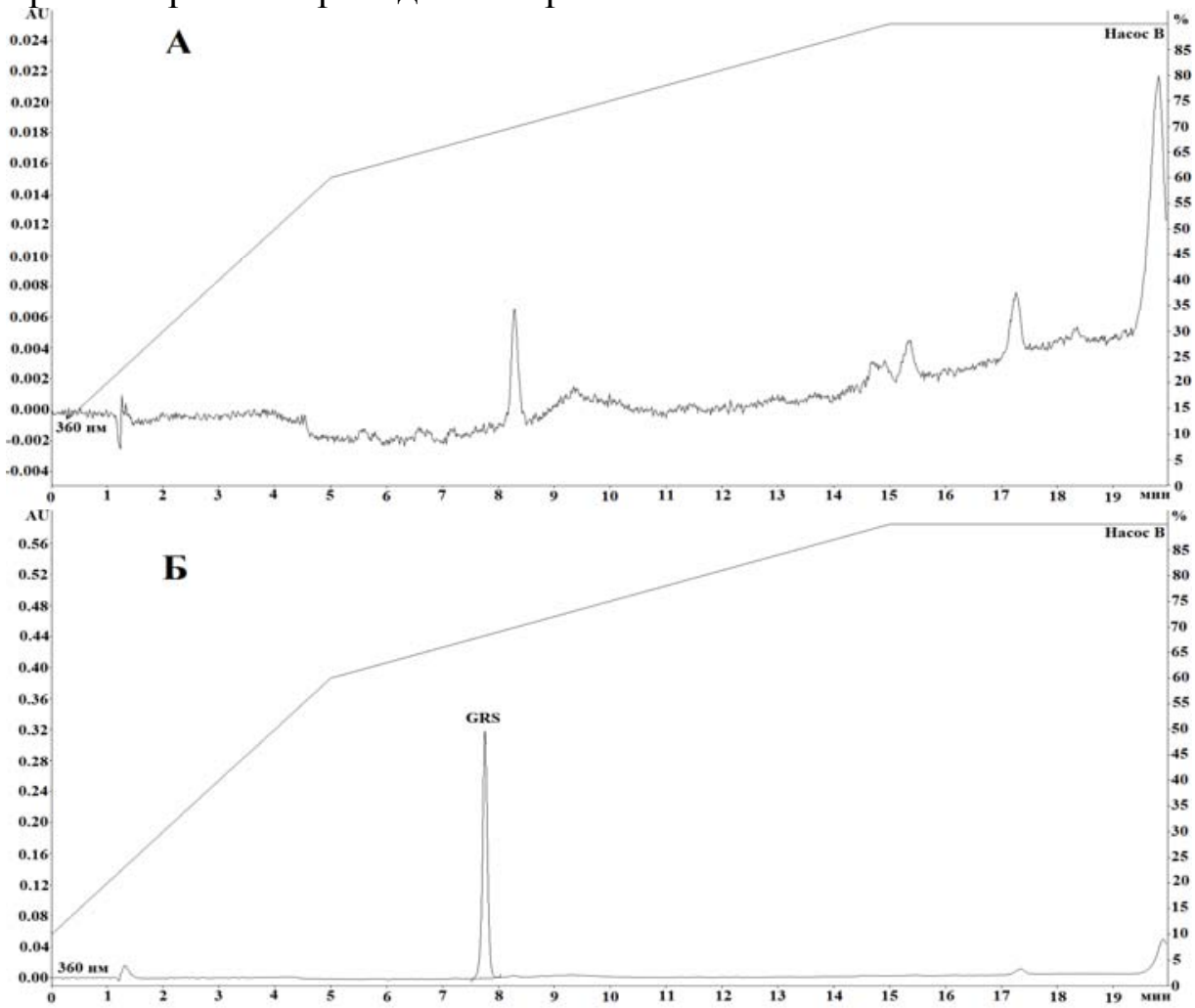

Рис. 3. Хроматограммы холостого образца плазмы крови (А) и образца плазмы

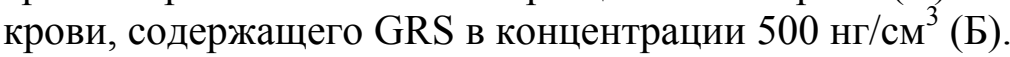

В ходе анализа выявлено отсутствие на хроматограммах холостых образцов пиков веществ, совпадающих по времени удерживания с пиком GRS.

Определены основные параметры пригодности хроматографической системы:

- время удерживания - 7.76 мин;

- эффективность колонки по пику GRS - 36973 TT;

- разрешение - 2.14;

- фактор асимметрии пика GRS - 1.1.

Предел обнаружения и нижний предел количественного определения. При установлении предела обнаружения и нижнего предела количественного определения (НПКО) использовали соотношения сигнал/шум, значения которых по требованиям должны составлять не менее 3:1 и 10:1 соответственно. Сравнивали величины сигналов, полученные для контрольного опыта (при отсутствии определяемого вещества в аналите), и для образцов с низкими концентрациями определяемого вещества. Установили, что пределом обнаружения GRS в плазме крови, согласно разработанной методике, является концентрация равная 5 нг $/ \mathrm{cm}^{3}$, нижним пределом количественного определения - $10 \mathrm{нг} / \mathrm{cm}^{3}$.

Линейность градуировочного графика. Проводили анализ 6 образцов плазмы

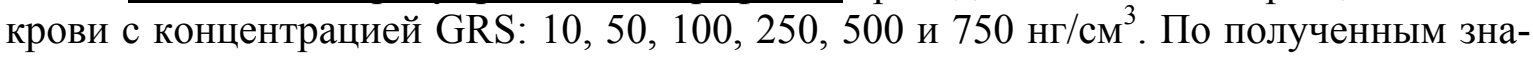


чениям площадей пиков был построен градуировочный график, представленный на рис. 4.

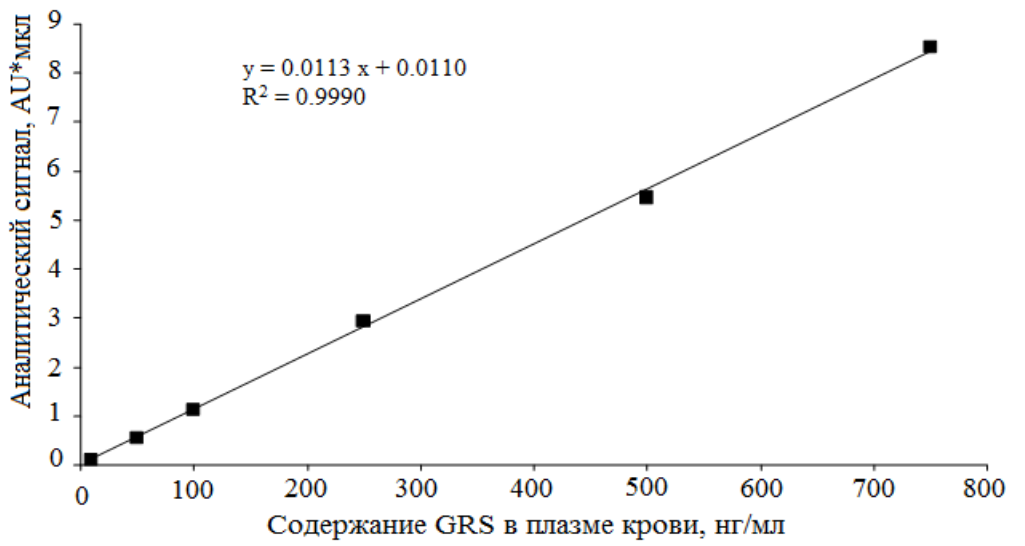

Рис. 4. Градуировочный график зависимости площади пика GRS от его концентрации в плазме крови

По полученной кривой (рис. 4) проводили обратный расчет концентраций градуировочных растворов. Отклонения концентраций градуировочных растворов, рассчитанных по графику, от фактических значений приведены в таблице 2.

Таблица 2. Отклонения концентраций градуировочных растворов от фактических значений

\begin{tabular}{|c|c|c|c|c|c|c|}
\hline 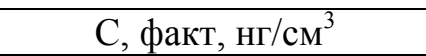 & 10.0 & 50.0 & 100.0 & 250.0 & 500.0 & 750.0 \\
\hline С рассчит, нг $/ \mathrm{cm}^{3}$ & 9.6 & 48.3 & 100.3 & 251.4 & 484.2 & 757.1 \\
\hline $\begin{array}{c}\text { Отклонение от фактиче- } \\
\text { ского значения, \% }\end{array}$ & 4.0 & 3.4 & 0.3 & 0.6 & 3.2 & 0.9 \\
\hline Норма, $\%$ & Не более 20 & \multicolumn{5}{|c|}{ Не более 15} \\
\hline
\end{tabular}

Полученные отклонения соответствуют нормам - не более $20 \%$ для нижнего предела количественного определения и не более $15 \%$ - для остальных точек.

Правильность и прецизионность.Для оценки правильности и прецизионности в условиях повторяемости, а также внутрилабораторной прецизионности, анализировали образцы плазмы крови, содержащие GRS в 4 различных концентрациях, перекрывающих собой диапазон градуировочной кривой: НПКО, тройная величина НПКО, $50 \%$ диапазона градуировочной кривой и $80 \%$ от верхнего диапазона градуировочной кривой, рассчитывая при этом количественное содержание по градуировочному графику. Для полученных значений концентраций были рассчитаны величины относительного стандартного отклонения (RSD, \%) и относительной погрешности $(\delta, \%)$, приведенные в таблицах 3-4.

Таблица 3. Правильность и прецизионность в условиях повторяемости

\begin{tabular}{|c|c|c|c|c|c|}
\hline $\begin{array}{c}\text { Номинальная } \\
\text { концентрация, } \\
\text { нг/см}{ }^{3}\end{array}$ & 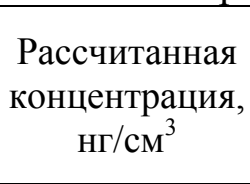 & 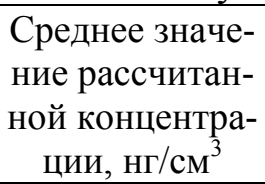 & $\begin{array}{c}\text { Отклонение от } \\
\text { номинальной } \\
\text { концентрации, \% }\end{array}$ & RSD, \% & $\delta, \%$ \\
\hline 1 & 2 & 3 & 4 & 5 & 6 \\
\hline \multirow{5}{*}{10.0} & 10.2 & \multirow{5}{*}{9.3} & \multirow{5}{*}{7.0} & \multirow{5}{*}{6.6} & \multirow{5}{*}{8.2} \\
\hline & 9.5 & & & & \\
\hline & 8.9 & & & & \\
\hline & 9.3 & & & & \\
\hline & 8.6 & & & & \\
\hline
\end{tabular}




\begin{tabular}{|c|c|c|c|c|c|}
\hline 1 & 2 & 3 & 4 & 5 & 6 \\
\hline \multirow{5}{*}{30.0} & 28.7 & \multirow{5}{*}{29.1} & \multirow{5}{*}{3.0} & \multirow{5}{*}{6.3} & \multirow{5}{*}{7.8} \\
\hline & 27.6 & & & & \\
\hline & 29.0 & & & & \\
\hline & 32.2 & & & & \\
\hline & 27.9 & & & & \\
\hline \multirow{5}{*}{375.0} & 359.8 & \multirow{5}{*}{376.5} & \multirow{5}{*}{0.4} & \multirow{5}{*}{4.2} & \multirow{5}{*}{5.2} \\
\hline & 388.5 & & & & \\
\hline & 381.4 & & & & \\
\hline & 360.1 & & & & \\
\hline & 392.7 & & & & \\
\hline \multirow{5}{*}{600.0} & 625.7 & \multirow{5}{*}{599.5} & \multirow{5}{*}{0.1} & \multirow{5}{*}{3.3} & \multirow{5}{*}{4.1} \\
\hline & 578.2 & & & & \\
\hline & 597.7 & & & & \\
\hline & 611.9 & & & & \\
\hline & 584.1 & & & & \\
\hline
\end{tabular}

Таблица 4. Внутрилабораторная прецизионность

\begin{tabular}{|c|c|c|c|c|}
\hline 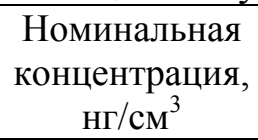 & 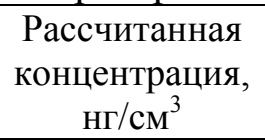 & $\begin{array}{c}\text { Среднее значение рассчи- } \\
\text { танной концентрации, } \\
\mathrm{Hг} / \mathrm{cm}^{3}\end{array}$ & $\mathrm{RSD}, \%$ & $\delta, \%$ \\
\hline \multirow{5}{*}{10.0} & 8.5 & \multirow{5}{*}{9.3} & \multirow{5}{*}{7.5} & \multirow{5}{*}{9.3} \\
\hline & 8.9 & & & \\
\hline & 10.3 & & & \\
\hline & 9.7 & & & \\
\hline & 9.2 & & & \\
\hline \multirow{5}{*}{30.0} & 27.5 & \multirow{5}{*}{29.5} & \multirow{5}{*}{5.1} & \multirow{5}{*}{6.3} \\
\hline & 29.7 & & & \\
\hline & 31,3 & & & \\
\hline & 28,6 & & & \\
\hline & 30,4 & & & \\
\hline \multirow{5}{*}{375.0} & 360.1 & \multirow{5}{*}{372.6} & \multirow{5}{*}{3.5} & \multirow{5}{*}{4.4} \\
\hline & 356.8 & & & \\
\hline & 382.7 & & & \\
\hline & 379,2 & & & \\
\hline & 384,4 & & & \\
\hline \multirow{5}{*}{600.0} & 617.5 & \multirow{5}{*}{596.0} & \multirow{5}{*}{2.9} & \multirow{5}{*}{3.6} \\
\hline & 571.2 & & & \\
\hline & 592.6 & & & \\
\hline & 605.1 & & & \\
\hline & 593.8 & & & \\
\hline
\end{tabular}

Полученные величины отклонений от номинальной концентрации соответствуют требованиям - не более $20 \%$ для нижнего предела количественного определения и не более $15 \%$ - для остальных точек, следовательно, доказана правильность разработанной биоаналитической методики. Значения относительного стандартного отклонения и относительной погрешности также соответствуют требованиям - не более $20 \%$ для нижнего предела количественного определения и не более $15 \%$ - для остальных точек, следовательно, доказаны прецизионность в условиях повторяемости и внутрилабораторная прецизионность данной методики.

Перенос. Перенос оценивался введением холостого образца после анализа образцов с концентрацией, соответствующей верхнему пределу градуировочной кри- 
вой. На полученной хроматограмме холостого образца не обнаружено пика GRS, следовательно, не происходит переноса сигнала от определяемого вещества в холостой образец после анализа образца плазмы крови с высокой концентрацией GRS.

Стабильность. Оценку стабильности проводили на образцах плазмы крови,

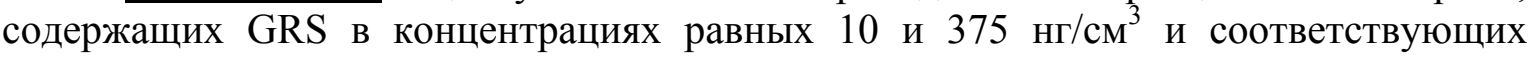
НПКО и 50\% диапазона градуировочной кривой. Образцы в растворенном виде и в виде сухих остатков были помещены в различные условия хранения: при комнатной температуре, в холодильник $\left(+3-6^{\circ} \mathrm{C}\right)$, в морозильную камеру $\left(-18-24^{\circ} \mathrm{C}\right)$. Образцы анализировали через 24 часа. Также модельные образцы плазмы крови, содержащие GRS, были подвергнуты многократному (3 цикла) размораживанию и замораживанию в течение 12 часов с последующим анализом. Свежеприготовленные образцы из той же серии анализировали сразу после приготовления.

При изучении стабильности было выявлено, что отклонения полученных значений концентраций варьируется в пределах от 0.29 до $7.31 \%$ и соответствуют требованиям (не более 10\%), что свидетельствует о стабильности образцов, содержащих GRS, в течение 24 часов при хранении в холодильнике и при комнатной температуpe, a также при многократном замораживании и размораживании.

\section{Заключение}

Разработана новая высокочувствительная биоаналитическая методика количественного определения нового инновационного антитромботического лекарственного средства GRS в плазме крови крыс методом ВЭЖХ с УФ-детектированием. Подобраны оптимальные условия пробоподготовки для извлечения GRS из биологической матрицы. Подтверждена пригодность разработанной методики путем ее валидации, доказаны селективность, линейность, правильность и прецизионность. Разработанная методика может быть применена для количественной оценки содержания GRS в плазме крови крыс при различных фармакокинетических исследованиях.

\section{Список литературы}

1. Ольбинская Л.И., Гофман А.М. Лечение и профилактика тромбозов. М. Вагриус. 2000. $196 \mathrm{c}$.

2. Чарная М.А., Морозов Ю.А. // Кардиология и сердечно-сосудистая хирургия. 2009. № 1. C. 34-40.

3. Bhatt D.L., Topol E.J. // Nature. Reviews. 2003. Vol. 2, pp.15-19. DOI: $10.1038 /$ nrd985

4. Староверов И.И. // Consilium medicum. 2000. T. 2. № 11. C. 20-23.

5. Фаворитов В.М. // Вестник Запорожского наиионального университета. 2011. № 1. C. 133-141.

6. Каркищенко Н.Н., Хоронько В.В., Сергеева С.А. и др. Фармакокинетика. Ростов. Феникс. 2001. 384 с.
7. Иванникова Е.В., Жердев В.П., Бойко С.С., Блынская Е.В. и др. // Фармакокинетика и фармакодинамика. 2013. № 2. С. 1-17.

8. Граник В.Г., Рябова С.Ю., Григорьев Н.Б. // Успехи химии. 1996. Т. 66. № 8. С. 792-807.

9. Сычев К.С. Практический курс жидкостной хроматографии. Москва: Техносфера, 2010. $272 \mathrm{c}$.

10.Сапрыкин Л.В. // Химический анализ. 2005. C. 20-36.

11.Сычев К.С. Подготовка пробы в газовой и жидкостной хроматографии. Кокоро. 2012. $155 \mathrm{c}$.

12.Anzillotti L., Odoardi S., Rossi S.S. // Forensic Science Int. 2014. Vol. 243. pp. 99-106. DOI: 10.1016/j.forsciint.2014.05.005 


\section{References}

1. Ol'binskaja L.I., Gofman A.M. Lechenie i profilaktika trombozov. M., 2000, $196 \mathrm{p}$.

2. Charnaja M.A., Morozov Ju.A, Kardiologija i serdechno-sosudistaja hirurgij, 2009, Vol. 1, pp. 34-40.

3. Bhatt D.L., Topol E.J., Nature. Reviews, 2003, Vol. 2, pp.15-19. DOI: 10.1038/nrd985

4. Staroverov I.I., Consilium medicum, 2000, Vol. 2, No 11. pp. 20-23.

5. Favoritov V.M., Vestnik Zaporozhskogo nacional'nogo universiteta, 2011, Vol. 1, pp. 133-141.

6. Karkishhenko N.N., Horon'ko V.V., Sergeeva S.A. Farmakokinetika, Rostov, Feniks, 2001, $384 \mathrm{p}$.

Леонов Клим Андреевич - аспирант кафедры физической и аналитической химии, Национальный исследовательский Томский политехнический университет, Томск

Вишенкова Дарья Александровна - аспирант кафедры физической и аналитической химии, Национальный исследовательский Томский политехнический университет, Томск

Бакибаев Абдигали Абдиманапович - профессор, д.х.н., ведущий научный сотрудник лаборатории органического синтеза химического факультета, Национальный исследовательский Томский государственный университет, Томск
7. Ivannikova E.V., Zherdev V.P., Bojko S.S., Blynskaja E.V. et al., Farmakokinetika $i$ farmakodinamika, 2013, Vol. 2, pp. 1-17.

8. Granik V.G., Rjabova S.Ju., Grigor'ev N.B., Uspehi himii, 1996, Vol. 66, No 8, pp. 792-807.

9. Sychev K.S., Prakticheskij kurs zhidkostnoj hromatografii, Kokoro, 2013, 272 p.

10. Saprykin L.V., Himicheskij analiz, 2005, pp. 20-36.

11. Sychev K.S., Podgotovka proby v gazovoj i zhidkostnoj hromatografii, Kokoro, 2012, $155 \mathrm{p}$.

12. Anzillotti L., Odoardi S., Rossi S.S., Forensic Science Int., 2014, Vol. 243, pp. 99-106. DOI: 10.1016/j.forsciint.2014.05.005

Leonov Klim A. - PhD student of Department of Physical and Analytical Chemistry, National Research Tomsk Polytechnic University, Tomsk, e-mail: leonov_k90@mail.ru

Vishenkova Darya A. - PhD student of Department of Physical and Analytical Chemistry, National Research Tomsk Polytechnic University, Tomsk

Bakibaev Abdigali A. - Professor, Doctor of Chemistry, Senior Researcher in Laboratory of organic synthesis Faculty of Chemistry, National Research Tomsk State University, Tomsk 